\title{
Reduced tissue and serum resistin expression as a clinical marker for esophageal squamous cell carcinoma
}

\author{
AMOS C. HUNG ${ }^{1,2}$, YEN-YUN WANG ${ }^{1-4}$, KUN-TSUNG LEE ${ }^{5,6}$, HUNG-HSING CHIANG $^{7}$, \\ YUK-KWAN CHEN ${ }^{3,4,6,8}$, JE-KANG DU ${ }^{3,6}$, CHUN-MING CHEN ${ }^{3,9}$, MICHAEL YUANCHIEN CHEN ${ }^{10,11}$, \\ KWEI-JING CHEN ${ }^{10,11}$, STEPHEN CHU-SUNG HU ${ }^{12,13}$ and SHYNG-SHIOU F. YUAN ${ }^{1,2,4,14,15}$
}

\footnotetext{
${ }^{1}$ Translational Research Center; ${ }^{2}$ Department of Medical Research, Kaohsiung Medical University Hospital;

${ }^{3}$ School of Dentistry; ${ }^{4}$ Center for Cancer Research; ${ }^{5}$ Department of Oral Hygiene, Kaohsiung Medical University;
} Departments of ${ }^{6}$ Dentistry and ${ }^{7}$ Surgery, Kaohsiung Medical University Hospital; ${ }^{8}$ Oral and Maxillofacial Imaging Center, Kaohsiung Medical University; ${ }^{9}$ Department of Radiation Oncology, Kaohsiung Medical University Hospital, Kaohsiung 807;

${ }^{10}$ Department of Dentistry, China Medical University Hospital; ${ }^{11}$ School of Dentistry, China Medical University,

Taichung 406; ${ }^{12}$ Department of Dermatology, College of Medicine, Kaohsiung Medical University;

${ }^{13}$ Department of Dermatology, Kaohsiung Medical University Hospital; ${ }^{14}$ Graduate Institute of

Medicine, College of Medicine, Kaohsiung Medical University; ${ }^{15}$ Department of Obstetrics and

Gynecology, Kaohsiung Medical University Hospital, Kaohsiung 807, Taiwan, R.O.C.

Received June 8, 2021; Accepted August 19, 2021

DOI: $10.3892 / \mathrm{ol} .2021 .13035$

\begin{abstract}
Esophageal cancer is one of the most common malignancies and leading cause of cancer-associated mortality worldwide. However, the molecular mechanisms underlying esophageal cancer progression and the development of clinical tools for effective diagnosis remain unclear. Resistin, which was originally identified as an adipose tissue-secretory factor, has been associated with obesity-related diseases, including certain types of cancer. Thus, the present study aimed to investigate the expression levels of resistin in tissue and serum specimens from patients with esophageal squamous cell carcinoma (ESCC) to determine the potential biological effects of resistin on ESCC cells. The results demonstrated that both tissue and serum resistin levels were significantly lower in patients with ESCC compared with healthy controls. In addition, resistin expression was positively associated with the body mass index of patients with ESCC. In vitro studies revealed that resistin inhibited the migratory ability of ESCC cells, while having no effect on ESCC cell proliferation. Taken together, these results suggest that resistin may have the potential to be developed into a clinical marker for ESCC. However, further studies are required to investigate resistin receptor expression and determine the potential involvement of resistin-associated biological
\end{abstract}

Correspondence to: Professor Shyng-Shiou F. Yuan, Graduate Institute of Medicine, College of Medicine, Kaohsiung Medical University, 100 Tzyou 1st Road, Kaohsiung 807, Taiwan, R.O.C. E-mail: yuanssf@kmu.edu.tw

Key words: adipocytokine, resistin, body mass index, esophageal cancer, adenylyl cyclase-associated protein 1, toll-like receptor 4 pathways, which may provide insight for future development of targeted therapies for resistin-mediated ESCC.

\section{Introduction}

Esophageal cancer ranks as the ninth most common type of cancer and the sixth cause of cancer-associated mortality worldwide $(1,2)$. According to GLOBOCAN, 604,000 new cases and 544,000 mortalities were attributed to esophageal cancer in 2020 , and the latter signified that $\sim 1 / 18$ cancer-associated mortality was caused by esophageal cancer worldwide (3). The two major histological subtypes for esophageal cancer are adenocarcinoma and squamous cell carcinoma (4). Esophageal squamous cell carcinoma (ESCC) is common in Asia and Africa, while esophageal adenocarcinoma is common in North America, Australia, the United Kingdom and Europe $(3,5)$. The main risk factors for esophageal cancer include smoking, tobacco or betel chewing, high alcohol consumption, pickled foods and hot foods and beverages $(3,6)$. The risk of esophageal cancer may be reduced by dietary factors, such as increased vegetable and fruit consumption $(7,8)$. Primary prevention, including control of smoking or alcohol consumption, is considered the most effective method to reduce esophageal cancer incidence and mortality rates $(4,9)$.

Resistin is a member of the cysteine-rich secretory protein family, which is composed of resistin-like molecules $(10,11)$. It is a protein comprised of 108 amino acids in humans, while its mouse homolog contains 114 amino acids (10). Resistin is secreted as a disulfide-linked homodimer $(10,12)$. While resistin was initially reported to be mainly secreted by adipocytes in rodents and associated with obesity and insulin resistance (10), subsequent studies have demonstrated that it is also secreted by preadipocytes, peripheral blood mononuclear cells and macrophages in humans (13-16), suggesting 
a complex biological role of resistin across different species. It has been confirmed that resistin is associated with several inflammatory diseases, such as rheumatoid arthritis and atherosclerosis $(15,17,18)$, and with malignancies including breast (19), endometrial (20), colorectal (21) and several types of head and neck cancers (22).

The present study aimed to analyze resistin expression in the sera and esophageal tumor tissues of patients with ESCC, and the correlation between resistin expression and clinicopathological characteristics in ESCC. In addition, the effect of resistin on cell migration and proliferation of ESCC were investigated in vitro, and the potential underlying mechanisms were further discussed.

\section{Materials and methods}

Human specimens. Human tissues and blood specimens were obtained from patients with ESCC who underwent surgery at the Division of Thoracic Surgery, Department of Surgery, Kaohsiung Medical University Hospital (Kaohsiung, Taiwan) between January 2009 and December 2014. Patients who received neoadjuvant chemotherapy or radiotherapy were included, while patients with a history of other malignancies and those who underwent esophageal surgery were excluded from the present study. The tumor grading system was classified according to the American Joint Committee on Cancer (AJCC) Cancer Staging Manual (7th edition; https://cancerstaging.org/), and lymph node metastasis was determined by examining the presence or absence of invading tumors in the lymph nodes.

Esophageal cancer tissues and paired adjacent normal esophageal tissues were resected from patients with ESCC $(n=73)$, while blood samples were collected from a different cohort of patients with ESCC ( $n=26$, including 25 males and one female; mean age, 54 years; age range, 35-77 years) and healthy subjects $(n=26$, including 25 males and one female; mean age, 52 years; age range, 38-69 years). The present study was approved by the Institutional Review Board of Kaohsiung Medical University Hospital (approval no. KMUH-IRB-20130627; Kaohsiung, Taiwan) and written informed consent was provided by all participants prior to this study.

Cell culture and reagents. The human ESCC cell line, KYSE70 was gifted by Dr Yi-Ching Wang at the Department of Pharmacology, National Cheng Kung University (Tainan, Taiwan), while the TE8 cell line was gifted by Dr Mien-Chie Hung at the University of Texas MD Anderson Cancer Center (Houston, Texas). KYSE70 cells were maintained in RPMI-1640 medium (Invitrogen; Thermo Fisher Scientific, Inc.), while TE8 cells were maintained in DMEM/F12 (Invitrogen; Thermo Fisher Scientific, Inc.). All cells were maintained in a humidified incubator with $5 \% \mathrm{CO}_{2}$ at $37^{\circ} \mathrm{C}$, and the cell culture media were supplemented with $10 \%$ fetal bovine serum, $100 \mathrm{U} / \mathrm{ml}$ penicillin, $100 \mu \mathrm{g} / \mathrm{ml}$ streptomycin (all Biological Industries) and $0.25 \mu \mathrm{g} / \mathrm{ml}$ amphotericin B (Biological Industries). Recombinant human resistin was purchased from PeproTech, Inc.

ELISA. Serum resistin levels in patients with ESCC and healthy controls were measured using the Human Resistin
ELISA kit (cat. no. EK-028-36, Phoenix Pharmaceuticals, Inc.), according to the manufacturer's instructions.

Cell migration assay. The migratory ability of cells was assessed via the Transwell assay (Corning, Inc.). KYSE70 cells were seeded into Transwell inserts at a density of $5 \times 10^{4}$ cells/insert and placed in 24-well plates with serum-free cell culture medium (Invitrogen; Thermo Fisher Scientific, Inc.) to form the upper chamber. Normal cell culture medium supplemented with $10 \%$ FBS was plated in the lower chamber. Following treatment with resistin $(0,25,50$ or $100 \mathrm{ng} / \mathrm{ml})$ at $37^{\circ} \mathrm{C}$ for $24 \mathrm{~h}$, cells on the upper chamber were removed using cotton swabs, while the migratory cells were fixed in $4 \%$ formaldehyde at room temperature for $15 \mathrm{~min}$, and stained with $0.2 \%$ crystal violet at room temperature for $10 \mathrm{~min}$, and observed under a light microscope with a $10 \mathrm{X}$ objective lens (total magnification, x100). Quantification of cell migration was performed using ImageJ software ver. $1.53 \mathrm{j}$ (National Institutes of Health; https://imagej.nih.gov/ij/).

Cell proliferation assay. Cell proliferation was assessed via the XTT assay (X4626, Sigma-Aldrich; Merck KGaA). KYSE70 or TE8 cells were seeded into 96 -well plates at a density of $5 \times 10^{3}$ cells/well and treated with resistin $(0,25$, 50 and $100 \mathrm{ng} / \mathrm{ml}$ ) at $37^{\circ} \mathrm{C}$ for $24-72 \mathrm{~h}$. Following treatment, $\mathrm{XTT}$ reagent was added into each well along with phenazine methosulfate (Sigma-Aldrich; Merck $\mathrm{KGaA}$ ) at $37^{\circ} \mathrm{C}$ for $2 \mathrm{~h}$, according to the manufacturer's instructions. Absorbance was measured at a wavelength of $475 \mathrm{~nm}$ (A1) using a spectrophotometry, with a nonspecific reference wavelength at $660 \mathrm{~nm}$ (A2) to calculate the final reading $(\triangle \mathrm{A}=\mathrm{A} 1-\mathrm{A} 2)$.

Immunohistochemistry (IHC). IHC analysis was performed to analyze resistin expression in esophageal cancer tissues and paired adjacent normal esophageal tissues, using the Leica Bond-Max automated IHC stainer (Leica Microsystems, Inc.), according to the manufacturer's instructions and our previous report (23). IHC staining with anti-resistin primary antibody (1:100; cat. no. sc-376336; Santa Cruz Biotechnology, Inc.) was determined independently and blindly by two pathologists using a modified H-score (24). Briefly, the percentage of positively stained cells was categorized as follows: $0,0-4 \% ; 1$, $5-24 \% ; 2,25-49 \% ; 3,50-74 \%$ and $4,75-100 \%$. The intensity of staining was categorized as follows: 0 , negative; 1 , weak; 2 , moderate and 3, strong. The total score for each sample was the product of positively stained cells (A) and intensity of staining (B), according to their categorized scores (ranging from $0-12$ by $\mathrm{A} x \mathrm{~B})$.

Patients were divided into low resistin expression $(n=55)$ and high resistin expression $(n=18)$ groups, and receiver-operating characteristic curve analysis was performed to determine optimal sensitivity and specificity for the cut-off point used in the present study (Fig. S1). For negative control in IHC staining, anti-resistin primary antibody was omitted and all other steps remained the same.

Oncomine database analysis. Resistin mRNA expression in ESCC tissues and adjacent normal tissues was analyzed using the Oncomine database (https://www.oncomine.org), which is a web-based data-mining platform with a collection of cancer 


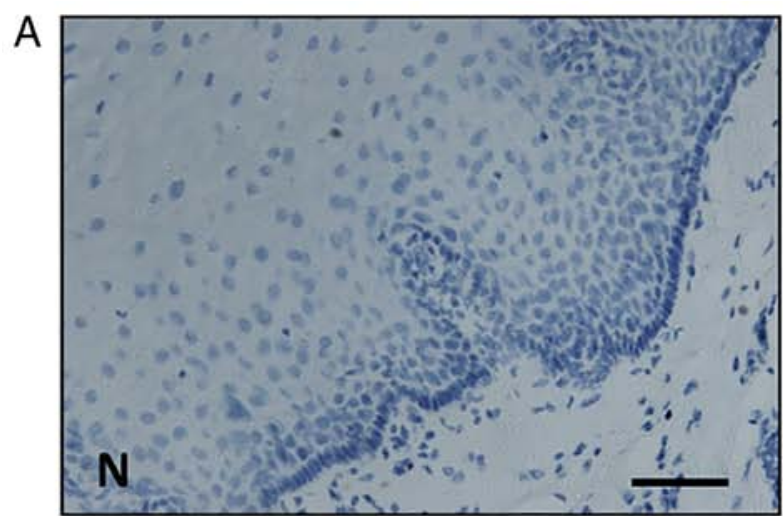

$\mathrm{B}$
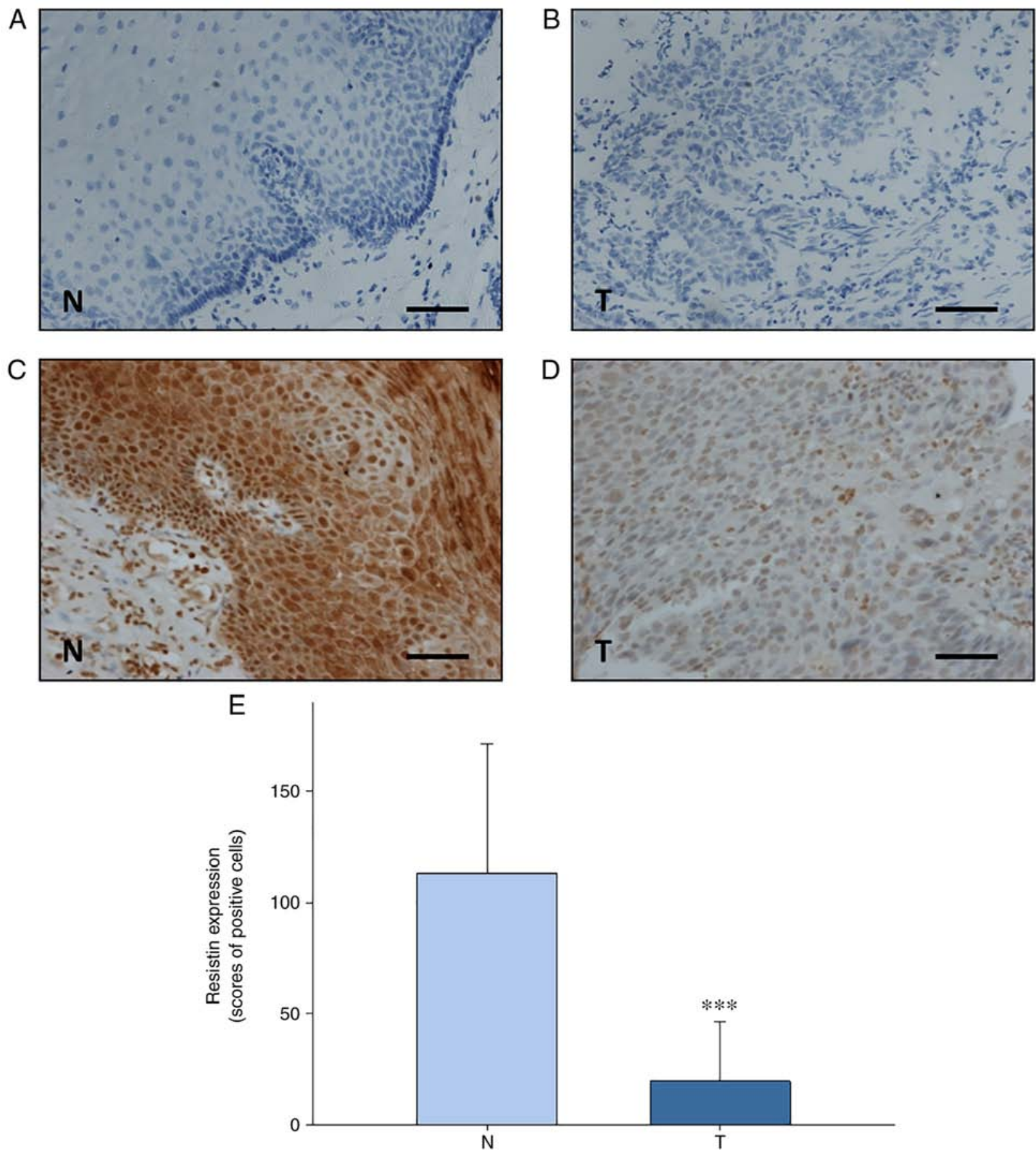

Figure 1. Resistin expression in esophageal tissues was detected via immunohistochemical analysis. Representative micrographs for negative controls of (A) adjacent normal esophageal tissues and (B) ESCC tissues. Representative micrographs of (C) adjacent normal esophageal tissues and (D) ESCC tissues. Scale bar, $100 \mu \mathrm{m}$. (E) Quantification of scored resistin expression in adjacent normal esophageal tissues and ESCC tissues. Paired student's t-test was used to compare difference between both groups. ${ }^{* * *} \mathrm{P}<0.001$. ESCC, esophageal squamous cell carcinoma; $\mathrm{N}$, adjacent normal esophageal tissues; T, ESCC tissues.

microarray datasets for comparing differential expression of genes between cancer tissues and normal tissues (25). All data analyzed by Oncomine were log-transformed and are illustrated as median-centered boxplots (25).

Statistical analysis. Statistical analysis was performed using SPSS v17 software (SPSS, Inc.). For in vitro studies, data are presented as the mean \pm SD from three independent experiments. Fisher's exact test was used to assess the association between resistin expression and the clinicopathological characteristics of patients with ESCC. Comparisons for the in situ or in vitro studies were calculated using either paired or unpaired Student's t-test where applicable, or one-way ANOVA followed by Dunnett's test, respectively. $\mathrm{P}<0.05$ was considered to indicate a statistically significant difference.

\section{Results}

Tissue resistin expression and clinical associations in patients with ESCC. IHC analysis revealed that resistin expression was significantly downreglated in esophageal tumor tissues compared with paired adjacent normal esophageal tissues 
Table I. Association between resistin expression and the clinicopathological characteristics of patients with esophageal squamous cell carcinoma $(n=73)$.

\begin{tabular}{|c|c|c|c|}
\hline \multirow[b]{2}{*}{ Characteristic } & \multicolumn{2}{|c|}{ Resistin expression } & \multirow[b]{2}{*}{ P-value } \\
\hline & Low, n (\%) & High, n (\%) & \\
\hline Sex, male & $55(75.3)$ & $18(24.7)$ & \\
\hline Alcohol consumption & & & 0.670 \\
\hline No & 7 (87.5) & $1(12.5)$ & \\
\hline Yes & $48(73.8)$ & $17(26.2)$ & \\
\hline Betel quid chewing & & & 0.287 \\
\hline No & $30(81.1)$ & $7(18.9)$ & \\
\hline Yes & $25(69.4)$ & $11(30.6)$ & \\
\hline Cigarette smoking & & & 0.182 \\
\hline No & $7(100.0)$ & $0(0.0)$ & \\
\hline Yes & $48(72.7)$ & $18(27.3)$ & \\
\hline $\mathrm{BMI}^{\mathrm{b}}$ & & & $0.042^{\mathrm{a}}$ \\
\hline Low & $25(92.6)$ & $2(7.4)$ & \\
\hline High & $20(69.0)$ & $9(31.0)$ & \\
\hline Histopathological grade & & & $>0.999$ \\
\hline I & $9(75.0)$ & $3(25.0)$ & \\
\hline II+III & $46(75.4)$ & $15(24.6)$ & \\
\hline Tumor size, $\mathrm{cm}$ & & & 0.393 \\
\hline $\mathrm{T} 1+\mathrm{T} 2$ & $19(82.6)$ & $4(17.4)$ & \\
\hline $\mathrm{T} 3+\mathrm{T} 4$ & $36(72.0)$ & $14(28.0)$ & \\
\hline Lymph node metastasis & & & 0.277 \\
\hline No & $28(82.4)$ & $6(17.6)$ & \\
\hline Yes & $27(69.2)$ & $12(30.8)$ & \\
\hline Chemotherapy & & & 0.242 \\
\hline No & $15(65.2)$ & $8(34.8)$ & \\
\hline Yes & $40(80.0)$ & $10(20.0)$ & \\
\hline Radiotherapy & & & 0.233 \\
\hline No & $13(65.0)$ & $7(35.0)$ & \\
\hline Yes & $42(79.3)$ & $11(20.7)$ & \\
\hline Recurrence & & & 0.772 \\
\hline No & $39(76.5)$ & $12(23.5)$ & \\
\hline Yes & $16(72.7)$ & $6(27.3)$ & \\
\hline Death & & & 0.758 \\
\hline No & $13(72.2)$ & $5(27.8)$ & \\
\hline Yes & $42(76.4)$ & $13(23.6)$ & \\
\hline
\end{tabular}

${ }^{\mathrm{a}} \mathrm{P}<0.05$. ${ }^{\mathrm{b}}$ Missing data due to loss of records, 17 . BMI, body mass index.

from patients with ESCC $(\mathrm{n}=73)(\mathrm{P}<0.001$; Fig. 1$)$. The present study assessed the association between resistin expression in ESCC tissues and the clinicopathological characteristics of the patients, who were stratified into high and low resistin expression groups determined by receiver-operating characteristic curve analysis (Fig. S1). As presented in Table I, resistin expression was significantly associated with body mass index (BMI) $(\mathrm{P}=0.042)$. However, no significant associations were observed between resistin expression and lifestyle factors (alcohol consumption, betal quid chewing or smoking),

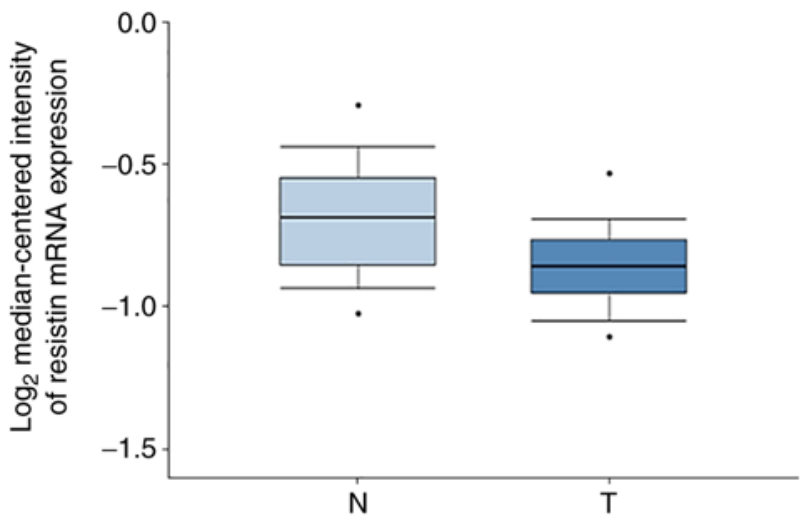

Figure 2. Resistin mRNA expression in esophageal tissues was detected using the Oncomine database. Resistin mRNA expression was downregulated in ESCC tissues compared with normal esophageal tissues. Data are presented as boxplots, with the maximum and minimum values indicated by black dots. ESCC, esophageal squamous cell carcinoma; $\mathrm{N}$, normal esophageal tissues; T, ESCC tissues.

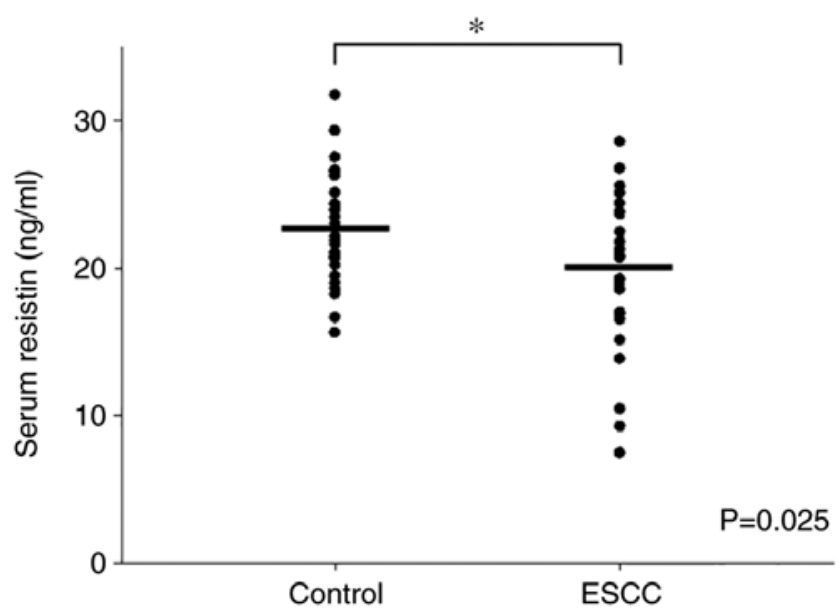

Figure 3. Serum resistin levels in patients with $\operatorname{ESCC}(n=26)$ and healthy individuals $(n=26)$ were detected via ELISA. The results demonstrated a higher mean serum resistin level in healthy individuals than patients with ESCC. Data are presented as dot plots, with the serum concentrations of each sample indicated by black dots. Unpaired Student's t-test was used to compare differences between both groups. ${ }^{*} \mathrm{P}<0.05$. ESCC, esophageal squamous cell carcinoma.

tumor characteristics (histopathological grade, tumor size or lymph node metastasis), treatment modalities (chemotherapy or radiotherapy) or patient outcomes (recurrence or death) (Table I).

The present study also analyzed resistin mRNA expression in ESCC tissues and normal esophageal tissues using the Oncomine database. The results demonstrated that resistin expression was higher in normal esophageal tissues compared with ESCC tissues (Fig. 2). These results suggest that the reduced resistin expression in ESCC tissues may serve as a diagnotic marker for clinical use.

Serum resistin levels in patients with ESCC. Given that circulating resistin is released by adipose tissues or the associated tumor tissues (19), the present study investigated serum resistin levels in patients with ESCC compared with healthy individuals via ELISA. Despite the heterogeneous expression 


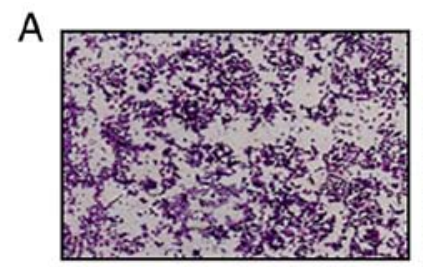

0

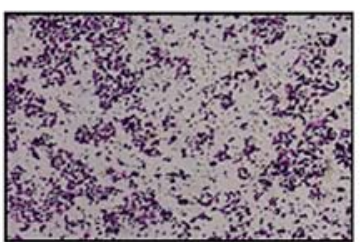

25

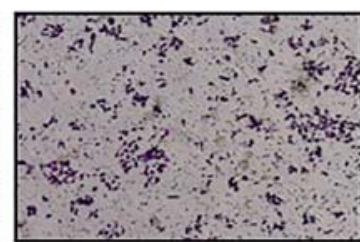

50

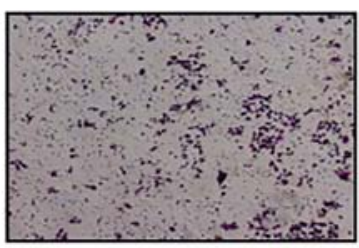

100

Resistin (ng/ml)

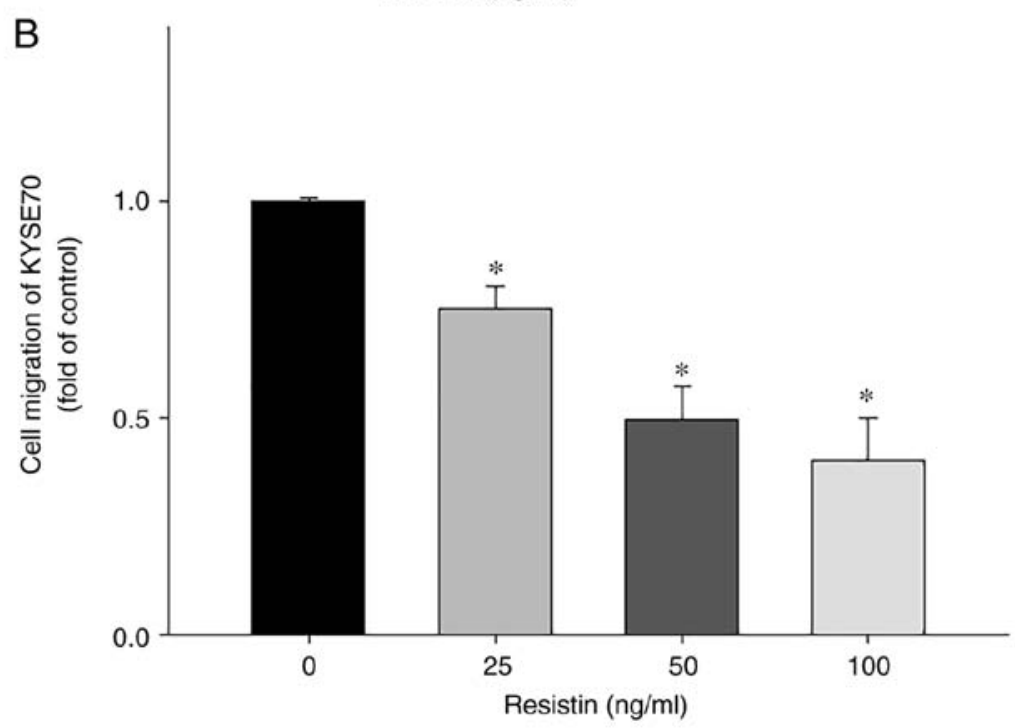

Figure 4. In vitro assessment of the migratory ability of human esophageal squamous cell carcinoma cells. (A) Representative micrographs depicting the migratory ability of KYSE70 cells treated with resistin via the Transwell assay. (B) Quantitation of the migratory ability of KYSE70 cells treated with different concentrations of resistin $(0,25,50$ and $100 \mathrm{ng} / \mathrm{ml})$. Data were obtained from three independent experiments. *P<0.05 vs. control.

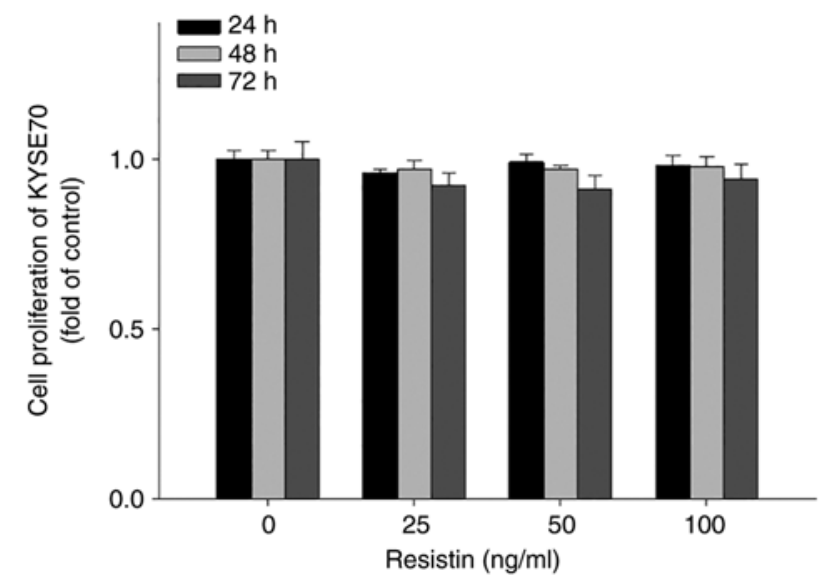

Figure 5. In vitro assessment of the proliferative ability of human esophageal squamous cell carcinoma cells. KYSE70 cells were treated with different concentrations of resistin $(0,25,50$ and $100 \mathrm{ng} / \mathrm{ml})$ for 24,48 or $72 \mathrm{~h}$, and cell proliferation was assessed via the XTT assay. Data were obtained from three independent experiments.

of serum resistin between individuals, the results demonstrated that the average serum resistin level was significantly lower in patients with ESCC $(n=26)$ compared with the healthy individuals $(\mathrm{n}=26)(\mathrm{P}=0.025$; Fig. 3 and Table SI). Notably, the serum resistin levels observed in the present study were within a similar range as previously reported (26). These results support the IHC findings of differential resistin expression between ESCC tissues and adjacent normal esophageal

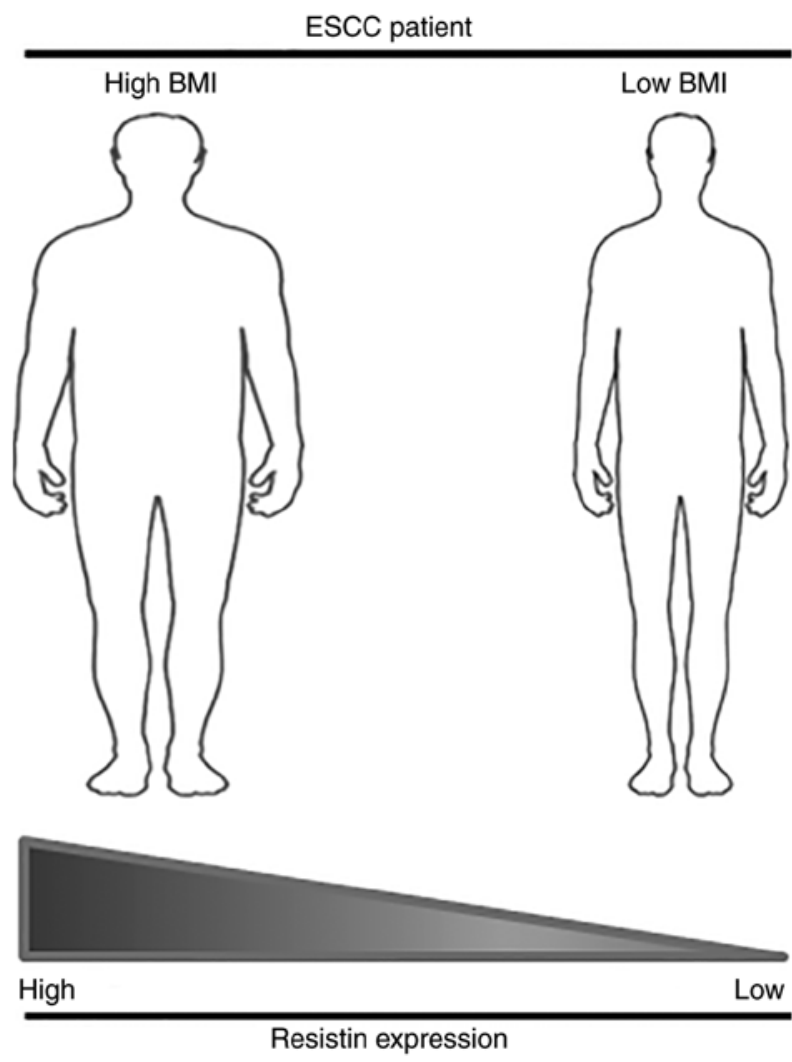

Figure 6. Schematic representation of the association between resistin expression and BMI in patients with ESCC. BMI, body mass index; ESCC, esophageal squamous cell carcinoma. 
tissues. In addition, the detection of serum resistin level may have the potential to be developed into a non-invasive liquid biopsy test for ESCC.

Resistin inhibits in vitro migration but not proliferation of ESCC cells. To investigate the biological effects of resistin on ESCC cell migration and proliferation, in vitro Transwell and XTT assays were performed, respectively. The results demonstrated that treatment with different concentrations of resistin significantly inhibited the migratory ability of KYSE70 cells in a dose-dependent manner $(25 \mathrm{ng} / \mathrm{ml}$ vs. control, $\mathrm{P}=0.023$; $50 \mathrm{ng} / \mathrm{ml}$ vs. control, $\mathrm{P}<0.001 ; 100 \mathrm{ng} / \mathrm{ml}$ vs. control, $\mathrm{P}<0.001$; Fig. 4), while treatment with resistin had no significant effect on KYSE70 cell proliferation (Fig. 5), suggesting that resistin may have a unique role in cell migration other than affecting proliferation of ESCC.

Similar results of the effect of resistin on the migration (Fig. S2A and B) and proliferation (Fig. S2C) of TE8 cells were observed. However, whether the phenomena of resistin-reduced in vitro cell migration can be translated into the cancer progression of ESCC in clinical settings is yet to be investigated. These results also suggest that the effect of resistin on ESCC cell migration may result from a signaling pathway that is distinctive from the signaling for ESCC proliferation.

\section{Discussion}

To the best of our knowledge, the present study was the first to demonstrate that resistin expression is downregulated in both ESCC tissues and serum samples of patients with ESCC compared with the controls. Previous studies have reported that resistin expression is upregulated in breast cancer $(23,27)$ and other types of cancer (28-31). However, the results of the present study may indicate a unique role for resistin in the diagnosis of esophageal cancer. The results demonstrated that tissue resistin expression was positively associated with the BMI of patients with ESCC. As presented in Fig. 6, this association may partly explain the discrepant resistin expression between the results of the present study and previous studies on different types of cancer (19-22), as elevated resistin expression has been associated with obesity $(10,32)$, but patients with esophageal cancer are usually on the opposite end of the body weight spectrum due to the occurrence of dysphagia $(33,34)$. A meta-analysis also revealed that a higher BMI $\left(\geq 25 \mathrm{~kg} / \mathrm{m}^{2}\right)$ is associated with lower risk of mortality in patients with ESCC (35), suggesting that obesity may have differential influence on ESCC compared with other types of cancer, such as breast cancer.

Previous studies have reported an association between increased resistin expression and $\operatorname{ESCC}(36,37)$. The molecular mechanism underlying these paradoxical findings remains elusive; however, factors that may affect the interpretation of clinical studies include selection criteria of patients and determination of high vs. low resistin expression levels via IHC analysis (19). The latter may be overcome with the advance of digital tissue image analysis, in which the automated scoring system for IHC can be more objective and consistent than manual assignment of the scores by different pathologists or trained examiners across laboratories $(38,39)$. The results of the present study demonstrated a significant association between
BMI and resistin expression; thus, prospective clinical studies may consider performing a primary stratification of patients with ESCC, based on their BMIs for further analysis of resistin expression in clinical samples.

Although resistin was originally found to be associated with obesity and insulin resistance in rodents (10), subsequent studies have reported a more complex role for resistin in humans, including its involvement in a number of inflammatory diseases and cancers $(40,41)$. The biological effects of resistin may occur via activation of its endogenous receptors (10). Adenylyl cyclase-associated protein 1 (CAP1) was the first receptor identified for human resistin in monocytes (42). In the study, overexpression of CAP1 enhanced resistin-mediated inflammatory responses, whereas these responses were abrogated by suppressing CAP1 expression (42). Subsequent studies revealed that elevated CAP1 expression is associated with breast tumor malignancy and poor patient survival (43). Our group recently demonstrated that toll-like receptor 4 (TLR4) is also a functional receptor for human resistin, and activation of the resistin/TLR4 signaling pathway is a critical step for the enhanced epithelial-to-mesenchymal transition and cancer stemness of breast cancer cells (23). Decorin and the receptor tyrosine kinase-like orphan receptor 1 are another two resistin receptors derived from mouse adipocyte progenitor cells $(44,45)$. Notably, increased expression of human decorin is associated with the transformation of oral epithelial cells into severe oral dysplasia-like phenotypes, although the particular role of resistin in this paradigm has not been assessed (46). Nevertheless, whether ESCC cells express these resistin receptors and whether they functionally affect resistin-associated cancer progression in patients with ESCC remain unknown. The results of the present study demonstrated that the migration ability of ESCC cells was reduced following treatment with resistin. In addition, the preliminary screening suggested that resistin-treated TE8 cells may have increased protein expression of epithelial markers, such as ZO-1, claudin-1 and E-cadherin, while decreasing the expression of mesenchymal markers, such as twist and slug (unpublished data). These suggest that the effect of resistin on ESCC cells may result from a different signaling pathway compared with those identified in breast cancer cells (19). As a matter of fact, the diverse signaling pathways of resistin receptors, such as STAT3, PI3K/AKT, mTOR, MAPK and NFKB, have been reported to participate in the regulation of tumor growth and metastasis in different types of cancer $(19,47)$. Furthermore, different expression levels of resistin receptors in ESCC may play an important role in cancer development. For example, the expression of apelin, one of the obesity-linked adipocytokines (48), is upregulated during adverse ESCC progression, whereas the expression of apelin receptor is downregulated in patients with advanced tumor stage and lymph node metastasis (37). Thus, further studies are required to investigate the functional expression of resistin receptors in ESCC, along with the detection of resistin expression.

In conclusion, the results of the present study suggest that resistin has the potential to be developed as a unique diagnostic marker for ESCC. However, due to the limitation of the cohort size in the present study, further studies with a larger sample size are required to validate the use of resistin as a prognostic marker for patients with ESCC. In addition, investigations into 
the expression of resistin receptors and associated signaling pathways in ESCC cells are required to provide a biological foundation for future development of targeted therapies for patients with resistin-mediated ESCC.

\section{Acknowledgements}

Not applicable.

\section{Funding}

The present study was financially supported by the Ministry of Health and Welfare of Taiwan (grant no. $\mathrm{MOH}$ W110-TDU-B-212-144016, Health and Welfare Surcharge of Tobacco Products), Kaohsiung Medical University Hospital (grant nos. KMUH105-5R32, KMUH106-6R41, KMUH106-6R83, KMUH107-7R36 and KMUH108-8R42) and Kaohsiung Medical University (Research Center grant no. KMU-DK108005; Center for Cancer Research grant nos. KMU-TC108A04-0 and KMU-TC108A04-1).

\section{Availability of data and materials}

The datasets used and/or analyzed during the current study are available from the corresponding author on reasonable request.

\section{Authors' contributions}

ACH, YYW, KTL, HHC, YKC, JKD, CMC, MYC, KJC, SCSH and SSFY conceived and designed the experiments. YYW, HHC, YKC, JKD and CMC performed the experiments. ACH, YYW, KTL, YKC, JKD, CMC and SSFY analyzed the data. YYW, KTL, YKC, JKD, CMC and SSFY provided experimental reagents and tools. ACH, YYW, SCSH and SSFY drafted the initial manuscript and revised the manuscript for important intellectual content. $\mathrm{ACH}$, YYW and SSFY confirm the authenticity of all the raw data. All authors have read and approved the final manuscript.

\section{Ethics approval and consent to participate}

The present study was approved by the Institutional Review Board of Kaohsiung Medical University Hospital (approval no. KMUH-IRB-20130627; Kaohsiung, Taiwan) and written informed consent was obtained prior to this study.

\section{Patient consent for publication}

Not applicable.

\section{Competing interests}

The authors declare that they have no competing interests.

\section{References}

1. Global Burden of Disease Cancer Collaboration; Fitzmaurice C, Dicker D, Pain A, Hamavid H, Moradi-Lakeh M, MacIntyre MF, Allen C, Hansen G, Woodbrook R, et al: The global burden of cancer 2013. JAMA Oncol 1: 505-527, 2015.
2. Global Burden of Disease Cancer Collaboration; Fitzmaurice C, Abate D, Abbasi N, AbbastabarH, Abd-Allah F, Abdel-Rahman O, Abdelalim A, Abdoli A, Abdollahpour I, et al: Global, regional, and national cancer incidence, mortality, years of life lost, years lived with disability, and disability-adjusted life-years for 29 cancer groups, 1990 to 2017: A systematic analysis for the global burden of disease study. JAMA Oncol 5: 1749-1768, 2019.

3. Sung H, Ferlay J, Siegel RL, Laversanne M, Soerjomataram I, Jemal A and Bray F: Global cancer statistics 2020: GLOBOCAN estimates of incidence and mortality worldwide for 36 cancers in 185 countries. CA Cancer J Clin 71: 209-249, 2021.

4. Lao-Sirieix P and Fitzgerald RC: Screening for oesophageal cancer. Nat Rev Clin Oncol 9: 278-287, 2012.

5. Edgren G, Adami HO, Weiderpass E and Nyren O: A global assessment of the oesophageal adenocarcinoma epidemic. Gut 62: 1406-1414, 2013.

6. Lagergren J, Smyth E, Cunningham D and Lagergren P: Oesophageal cancer. Lancet 390: 2383-2396, 2017.

7. Hajizadeh B, Jessri M, Moasheri SM, Rad AH and Rashidkhani B: Fruits and vegetables consumption and esophageal squamous cell carcinoma: A case-control study. Nutr Cancer 63: 707-713, 2011.

8. Liu J, Wang J, Leng Y and Lv C: Intake of fruit and vegetables and risk of esophageal squamous cell carcinoma: A meta-analysis of observational studies. Int J Cancer 133: 473-485, 2013.

9. Bosetti C, Franceschi S, Levi F, Negri E, Talamini R and La Vecchia C: Smoking and drinking cessation and the risk of oesophageal cancer. Br J Cancer 83: 689-691, 2000.

10. Steppan CM, Bailey ST, Bhat S, Brown EJ, Banerjee RR, Wright CM, Patel HR, Ahima RS and Lazar MA: The hormone resistin links obesity to diabetes. Nature 409: 307-312, 2001.

11. Steppan CM, Brown EJ, Wright CM, Bhat S, Banerjee RR, Dai CY, Enders GH, Silberg DG, Wen X, Wu GD and Lazar MA: A family of tissue-specific resistin-like molecules. Proc Natl Acad Sci USA 98: 502-506, 2001.

12. Banerjee RR and Lazar MA: Dimerization of resistin and resistin-like molecules is determined by a single cysteine. $\mathrm{J}$ Biol Chem 276: 25970-25973, 2001

13. McTernan PG, McTernan CL, Chetty R, Jenner K, Fisher FM, Lauer MN, Crocker J, Barnett AH and Kumar S: Increased resistin gene and protein expression in human abdominal adipose tissue. J Clin Endocrinol Metab 87: 2407, 2002.

14. Patel L, Buckels AC, Kinghorn IJ, Murdock PR, Holbrook JD, Plumpton C, Macphee $\mathrm{CH}$ and Smith SA: Resistin is expressed in human macrophages and directly regulated by PPAR gamma activators. Biochem Biophys Res Commun 300: 472-476, 2003.

15. Bokarewa M, Nagaev I, Dahlberg L, Smith U and Tarkowski A: Resistin, an adipokine with potent proinflammatory properties. J Immunol 174: 5789-5795, 2005.

16. Curat CA, Wegner V, Sengenès C, Miranville A, Tonus C, Busse R and Bouloumié A: Macrophages in human visceral adipose tissue: Increased accumulation in obesity and a source of resistin and visfatin. Diabetologia 49: 744-747, 2006.

17. Lehrke M, Reilly MP, Millington SC, Iqbal N, Rader DJ and Lazar MA: An inflammatory cascade leading to hyperresistinemia in humans. PLoS Med 1: e45, 2004.

18. Reilly MP, Lehrke M, Wolfe ML, Rohatgi A, Lazar MA and Rader DJ: Resistin is an inflammatory marker of atherosclerosis in humans. Circulation 111: 932-939, 2005.

19. Wang YY, Hung AC, Lo S and Yuan SF: Adipocytokines visfatin and resistin in breast cancer: Clinical relevance, biological mechanisms, and therapeutic potential. Cancer Lett 498: 229-239, 2021.

20. Hlavna M, Kohut L, Lipkova J, Bienertova-Vasku J, Dostalova Z, Chovanec J and Vasku A: Relationship of resistin levels with endometrial cancer risk. Neoplasma 58: 124-128, 2011.

21. Danese E, Montagnana M,Minicozzi AM,Bonafini S, Ruzzenente O, Gelati M, De Manzoni G, Lippi G and Guidi GC: The role of resistin in colorectal cancer. Clin Chim Acta 413: 760-764, 2012.

22. Tzanavari T, Tasoulas J, Vakaki C, Mihailidou C, Tsourouflis G and Theocharis S: The role of adipokines in the establishment and progression of head and neck neoplasms. Curr Med Chem 26: 4726-4748, 2019

23. Wang $\mathrm{CH}$, Wang PJ, Hsieh YC, Lo S, Lee YC, Chen YC, Tsai CH, Chiu WC, Chu-Sung Hu S, Lu CW, et al: Resistin facilitates breast cancer progression via TLR4-mediated induction of mesenchymal phenotypes and stemness properties. Oncogene 37: 589-600, 2018.

24. Detre S, Saclani Jotti G and Dowsett M: A ‘quickscore' method for immunohistochemical semiquantitation: Validation for oestrogen receptor in breast carcinomas. J Clin Pathol 48: 876-878, 1995 . 
25. Rhodes DR, Yu J, Shanker K, Deshpande N, Varambally R, Ghosh D, Barrette T, Pandey A and Chinnaiyan AM: ONCOMINE: A cancer microarray database and integrated data-mining platform. Neoplasia 6: 1-6, 2004.

26. Assiri AM and Kamel HF: Evaluation of diagnostic and predictive value of serum adipokines: Leptin, resistin and visfatin in postmenopausal breast cancer. Obes Res Clin Pract 10: 442-453, 2016.

27. Lee YC, Chen YJ, Wu CC, Lo S, Hou MF and Yuan SS: Resistin expression in breast cancer tissue as a marker of prognosis and hormone therapy stratification. Gynecol Oncol 125: 742-750, 2012.

28. Karapanagiotou EM, Tsochatzis EA, Dilana KD, Tourkantonis I, Gratsias I and Syrigos KN: The significance of leptin, adiponectin, and resistin serum levels in non-small cell lung cancer (NSCLC). Lung Cancer 61: 391-397, 2008.

29. Kerem M, Ferahkose Z, Yilmaz UT, Pasaoglu H, Ofluoglu E, Bedirli A, Salman B, Sahin TT and Akin M: Adipokines and ghrelin in gastric cancer cachexia. World J Gastroenterol 14: 3633-3641, 2008.

30. Nakajima TE, Yamada Y, Hamano T, Furuta K, Gotoda T, Katai H, Kato K, Hamaguchi T and Shimada Y: Adipocytokine levels in gastric cancer patients: Resistin and visfatin as biomarkers of gastric cancer. J Gastroenterol 44: 685-690, 2009.

31. Gonullu G, Kahraman H, Bedir A, Bektas A and Yucel I: Association between adiponectin, resistin, insulin resistance, and colorectal tumors. Int J Colorectal Dis 25: 205-212, 2010.

32. Tripathi D, Kant S, Pandey S and Ehtesham NZ: Resistin in metabolism, inflammation, and disease. FEBS J 287: 3141-3149, 2020.

33. Nitenberg G and Raynard B: Nutritional support of the cancer patient: Issues and dilemmas. Crit Rev Oncol Hematol 34: $137-168,2000$

34. Enzinger PC and Mayer RJ: Esophageal cancer. N Engl J Med 349: 2241-2252, 2003.

35. Fahey PP, Mallitt KA, Astell-Burt T, Stone G and Whiteman DC: Impact of pre-diagnosis behavior on risk of death from esophageal cancer: A systematic review and meta-analysis. Cancer Causes Control 26: 1365-1373, 2015.

36. Nakajima TE, Yamada Y, Hamano T, Furuta K, Oda I, Kato H, Kato K, Hamaguchi T and Shimada Y: Adipocytokines and squamous cell carcinoma of the esophagus. J Cancer Res Clin Oncol 136: 261-266, 2010.

37. Diakowska D, Markocka-Maczka K, Nienartowicz M, Rosinczuk J and Krzystek-Korpacka M: Assessment of apelin, apelin receptor, resistin, and adiponectin levels in the primary tumor and serum of patients with esophageal squamous cell carcinoma. Adv Clin Exp Med 28: 671-678, 2019.
38. Aeffner F, Wilson K, Martin NT, Black JC, Hendriks CLL, Bolon B, Rudmann DG, Gianani R, Koegler SR, Krueger J and Young GD: The gold standard paradox in digital image analysis: Manual versus automated scoring as ground truth. Arch Pathol Lab Med 141: 1267-1275, 2017.

39. Bankhead P, Fernández JA, McArt DG, Boyle DP, Li G, Loughrey MB, Irwin GW, Harkin DP, James JA, McQuaid S, et al: Integrated tumor identification and automated scoring minimizes pathologist involvement and provides new insights to key biomarkers in breast cancer. Lab Invest 98: 15-26, 2018.

40. Tilg H and Moschen AR: Adipocytokines: Mediators linking adipose tissue, inflammation and immunity. Nat Rev Immunol 6: 772-783, 2006.

41. Codoner-Franch P and Alonso-Iglesias E: Resistin: Insulin resistance to malignancy. Clin Chim Acta 438: 46-54, 2015.

42. Lee S, Lee HC, Kwon YW, Lee SE, Cho Y, Kim J, Lee S, Kim JY, Lee J, Yang HM, et al: Adenylyl cyclase-associated protein 1 is a receptor for human resistin and mediates inflammatory actions of human monocytes. Cell Metab 19: 484-497, 2014.

43. Rosendahl AH, Bergqvist M, Lettiero B, Kimbung S and Borgquist S: Adipocytes and obesity-related conditions jointly promote breast cancer cell growth and motility: Associations with CAP1 for prognosis. Front Endocrinol (Lausanne) 9: 689, 2018.

44. Daquinag AC, Zhang Y, Amaya-Manzanares F, Simmons PJ and Kolonin MG: An isoform of decorin is a resistin receptor on the surface of adipose progenitor cells. Cell Stem Cell 9: 74-86, 2011.

45. Sanchez-Solana B, Laborda J and Baladron V: Mouse resistin modulates adipogenesis and glucose uptake in 3T3-L1 preadipocytes through the ROR1 receptor. Mol Endocrinol 26: 110-127, 2012.

46. Banerjee AG, Bhattacharyya I, Lydiatt WM and Vishwanatha JK: Aberrant expression and localization of decorin in human oral dysplasia and squamous cell carcinoma. Cancer Res 63: 7769-7776, 2003

47. Sudan SK, Deshmukh SK, Poosarla T, Holliday NP, Dyess DL, Singh AP and Singh S: Resistin: An inflammatory cytokine with multi-faceted roles in cancer. Biochim Biophys Acta Rev Cancer 1874: 188419, 2020.

48. Wysocka MB, Pietraszek-Gremplewicz K and Nowak D: The role of apelin in cardiovascular diseases, obesity and cancer. Front Physiol 9: 557, 2018.

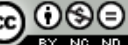

This work is licensed under a Creative Commons Attribution-NonCommercial-NoDerivatives 4.0 International (CC BY-NC-ND 4.0) License. 